\title{
Visible-light Promoted Atom Transfer Radical Addition-Elimination (ATRE) Reaction for the Synthesis of Fluoroalkylated Alkenes Using DMA as Electron-donor
}

\author{
Wen-Wen $\mathrm{Xu}^{1, \dagger}{ }^{\text {, Le Wang }}{ }^{2, \dagger}{ }^{\text {, Ting Mao }}{ }^{1}$, Jiwei $\mathrm{Gu}^{3}$, Xiao-Fei $\mathrm{Li}^{2,4, *}$ and Chun-Yang $\mathrm{He}^{1,4, * \mathbb{C}}$ \\ 1 Key Laboratory of Biocatalysis \& Chiral Drug Synthesis of Guizhou Province, Generic Drug Research Center \\ of Guizhou Province. School of Pharmacy, Zunyi Medical University, Zunyi 563003, China; \\ xuww20191213@163.com (W.-W.X.); 18585310741@163.com (T.M.) \\ 2 Basic Medical School, Zunyi Medical University, Zunyi 563003, China; wangle526@sina.com \\ 3 School of Medicine, Washington University in St. Louis, St. Louis, MO 63110, United States; \\ jiweigu@wustl.edu \\ 4 Key Laboratory of Basic Pharmacology of Ministry of Education and Joint International Research Laboratory \\ of Ethnomedicine of Ministry of Education, School of Pharmacy, Zunyi Medical University, \\ Zunyi 563003, China \\ * Correspondence: lixiaofei@zmu.edu.cn (X.-F.L.); hechy2002@163.com (C.-Y.H.) \\ + These authors contributed equally to this work.
}

Academic Editor: Davide Ravelli

Received: 12 December 2019; Accepted: 21 January 2020; Published: 24 January 2020

\begin{abstract}
Here, we describe a mild, catalyst-free and operationally-simple strategy for the direct fluoroalkylation of olefins driven by the photochemical activity of an electron donor-acceptor (EDA) complex between DMA and fluoroalkyl iodides. The significant advantages of this photochemical transformation are high efficiency, excellent functional group tolerance, and synthetic simplicity, thus providing a facile route for further application in pharmaceuticals and life sciences.
\end{abstract}

Keywords: fluoroalkyl iodides; EDA; noncovalent interaction; fluoroalkylated alkenes; DMA

\section{Introduction}

Owing to their tendency to alter the lipophilicity, metabolic stability, and electronic properties of organic molecules, fluorinated organic compounds have been widely used in medicinal chemistry, and material sciences [1-9]. Therefore, the development of safer, less toxic and more selective methods to introduce fluorinated functional groups into organic molecules has become an intensive topic of synthetic organic chemistry [10-19].

Alkenes play a ubiquitous role in the realm of chemical synthesis due to their enriched reactivity and abundance, fluoroalkylation of carbon-carbon double bonds is an attractive method for accessing fluorine containing compounds. Since 1945, atom transfer radical addition (ATRA) has extensively been utilized for fluoroalkylation of alkenes [20-29]. However, the preparation of alkenes containing fluorinated functional groups via Heck-type reaction were less studied owning to the lack of efficient and general strategies [30-32]. In the past 10 years, some powerful strategies have been developed to realize such transformation [20,21,33-36]. One of the major improvements has been made via photo-excited catalyst such as $\mathrm{Ru} / \mathrm{Ir}$ complexes and organic dyes [21,33]. Very recently, non-covalent interaction initiated fluoroalkylation reaction has emerged as an attractive strategy [37-47]. Inspired by our previous studies in this field [48-51], we envision that if the solvent can serve as an electron donor compound, the reactions would be simpler. Here, we demonstrate a 
mild, catalyst-free and operationally-simple strategy for the direct fluoroalkylation of olefins driven by the photochemical activity of electron donor-acceptor (EDA) complex between DMA and fluoroalkyl iodides. The significant advantages of this photochemical transformation are high efficiency, excellent functional group tolerance, and synthetic simplicity [52].

\section{Results}

We initially probed this catalyst-free fluoroalkylation reaction by using readily available tert-butyl allylcarbamate 1a and ethyl iododifluoroacetate $2 \mathbf{a}$ (1.5 equiv) as model substrates. $29 \%$ yield of atom transfer radical addition (ATRA) product $4 \mathbf{a}$ was obtained when the reaction was performed with $\mathrm{K}_{3} \mathrm{PO}_{4}$ (2.0 equiv) in MeCN and irradiated by blue LEDs for $16 \mathrm{~h}$. After a series of reaction media were screened (Table 1, entries 2-8), THF, Toluene and dioxane were not suitable for this transformation, and $10 \%$ yield of desired product was obtained when DMSO was used as solvent. Both 3a and $4 \mathbf{a}$ were obtained when DMA and DMF were used. To improve the selectivity of this transformation, a variety of different bases were examined utilizing DMA as solvent for this reaction (Table 1, entries 8-11). Among them, KOAc was the best choice and afforded 3a in $64 \%$ yield (Table 1, entry 11). Finally, different light sources were tested, the yield increased to $95 \%$ when the reaction mixtures were irradiated under purple LEDs (Table 1, entry 13), no desired product was observed when control experiments were carried out in the absence of light or base, demonstrating the photochemical nature of this transformation (Table 1, entries 14, 15).

Table 1. Representative results for optimization of visible light-mediated reaction of $\mathbf{1 a}$ and $\mathbf{2 a}$.

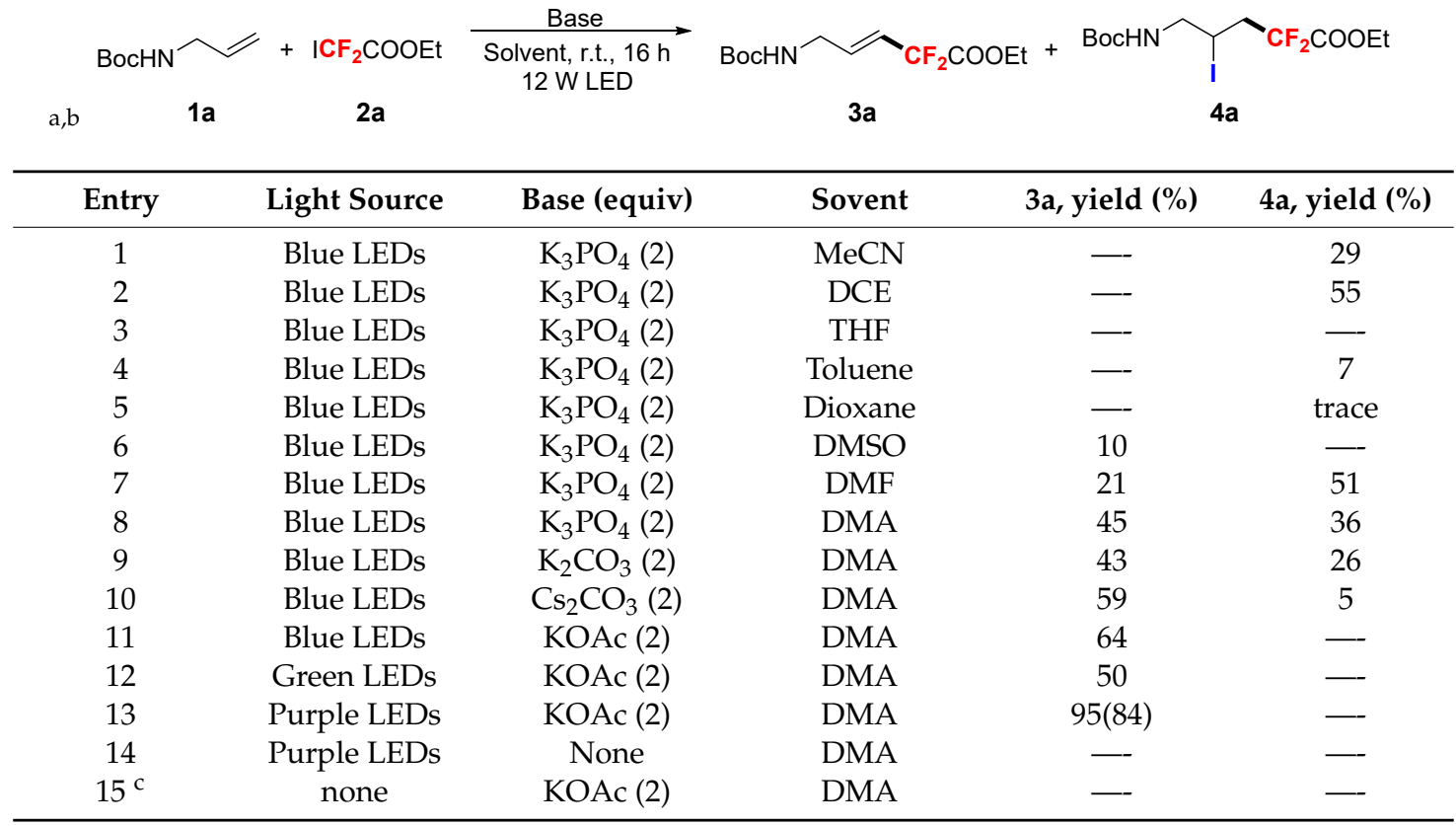

a Reaction conditions: (unless otherwise specified): $\mathbf{1 a}(0.3 \mathrm{mmol}, 1.0$ equiv), $\mathbf{2 a}(0.45 \mathrm{mmol}, 1.5$ equiv), anhydrous solvent $(2 \mathrm{~mL})$, r.t. under $\mathrm{Ar}$, irritated under visible light for $16 \mathrm{~h}$. ${ }^{\mathrm{b}}$ Determined by ${ }^{19} \mathrm{~F}$ NMR spectroscopy using fluorobenzene as an internal standard, and the number within parentheses represents the yield of the isolated product. ${ }^{\mathrm{c}}$ The reaction was performed without light.

With the optimum reaction conditions established, various alkenes were explored. As shown in Scheme 1, The reaction exhibited good functional group tolerance. A range of functional groups, such as esters (3c), methoxyl (3d), and even unprotected hydroxyl group (3e) generally were compatible with the reaction and moderate to good yields were obtained. Then, styrenes were also evaluated, and we were pleased to find that styrenes all performed well under the optimized reaction conditions, providing the corresponding products in good to excellent yields ( $\mathbf{3} \mathbf{f}-\mathbf{n})$. Importantly, substrate with steric hindrance could also undergo this transformation smoothly (3o). This reaction system is also 
amenable to the use of other commercial perfluoroalkyl iodides, such as $\mathrm{C}_{4} \mathrm{~F}_{9} \mathrm{I}, \mathrm{C}_{6} \mathrm{~F}_{13} \mathrm{I}$ and $\mathrm{C}_{8} \mathrm{~F}_{17} \mathrm{I}$ (Scheme 1, 3p-s).

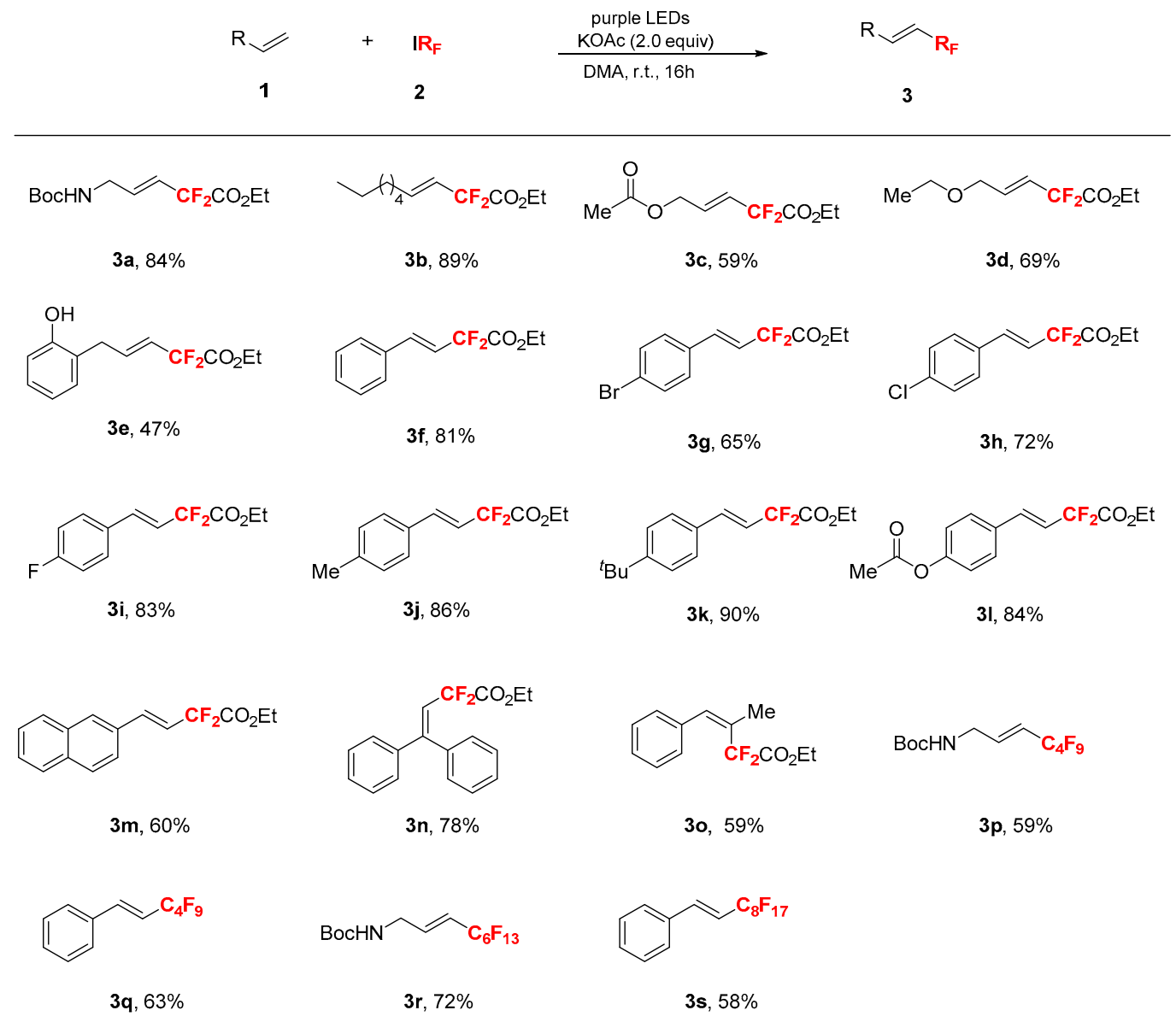

Scheme 1. Atom Transfer Radical Addition-Elimination (ATRE) reaction for the synthesis of fluoroalkylated alkenes $a, b$. ${ }^{a}$ Reaction conditions (unless otherwise specified): $\mathbf{1}$ ( $0.3 \mathrm{mmol}, 1.0$ equiv), $2(0.45 \mathrm{mmol}, 1.5$ equiv), KOAc $(0.6 \mathrm{mmol}, 2.0$ equiv $)$ in anhydrous DMA $(2.0 \mathrm{~mL})$, r.t. under Ar, purple LEDs, for $16 \mathrm{~h} .{ }^{\mathrm{b}}$ Yield of isolated product.

To gain insight into the mechanism of this reaction, several experiments were performed. The reaction was completely suppressed when a radical scavenger TEMPO (1.0 equiv) was added as an additive under the standard reaction conditions (Scheme 2a). Furthermore, a radical clock experiment was conducted. The ring-expanded product 7 was formed when $\mathbf{2 a}$ was treated with $\alpha$-cyclopropylstyrene (6) in the absence of $1 \mathrm{a}$ (Scheme 2b). Optical absorption spectra of the reactants found that the absorption was obvious strengthened when DMA and $R_{F} I$ were mixed (Scheme 2c, for details, see Supplementary Materials), which indicated a non-covalent interaction occurred between them. Moreover, this conclusion was further confirmed by a Job's plot (Scheme 2d, for details, see Supplementary Materials). Finally, compound $4 \mathbf{a}$ was totally converted to 3a under optimized condition in the dark (Scheme 2e, for details, see Supplementary Materials). This result indicated that the reaction was performed via atom transfer radical addition elimination pathway. 
a

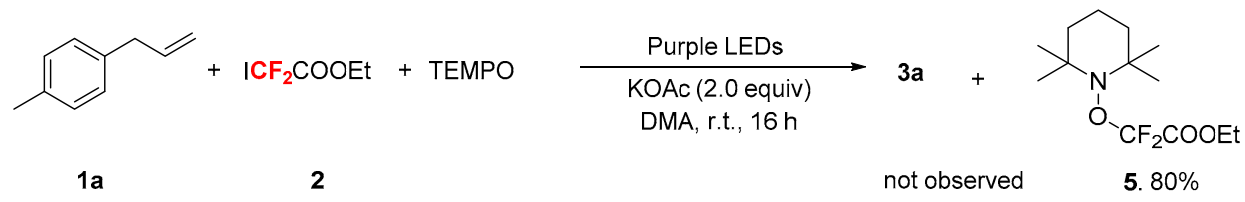

b

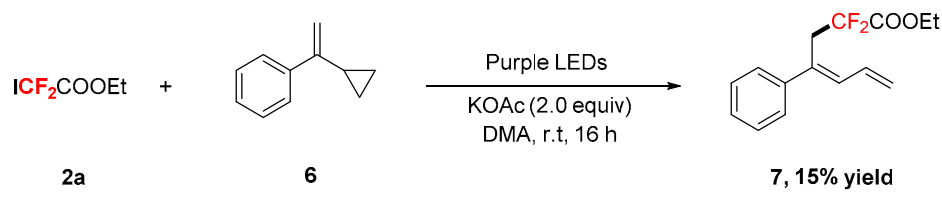

C
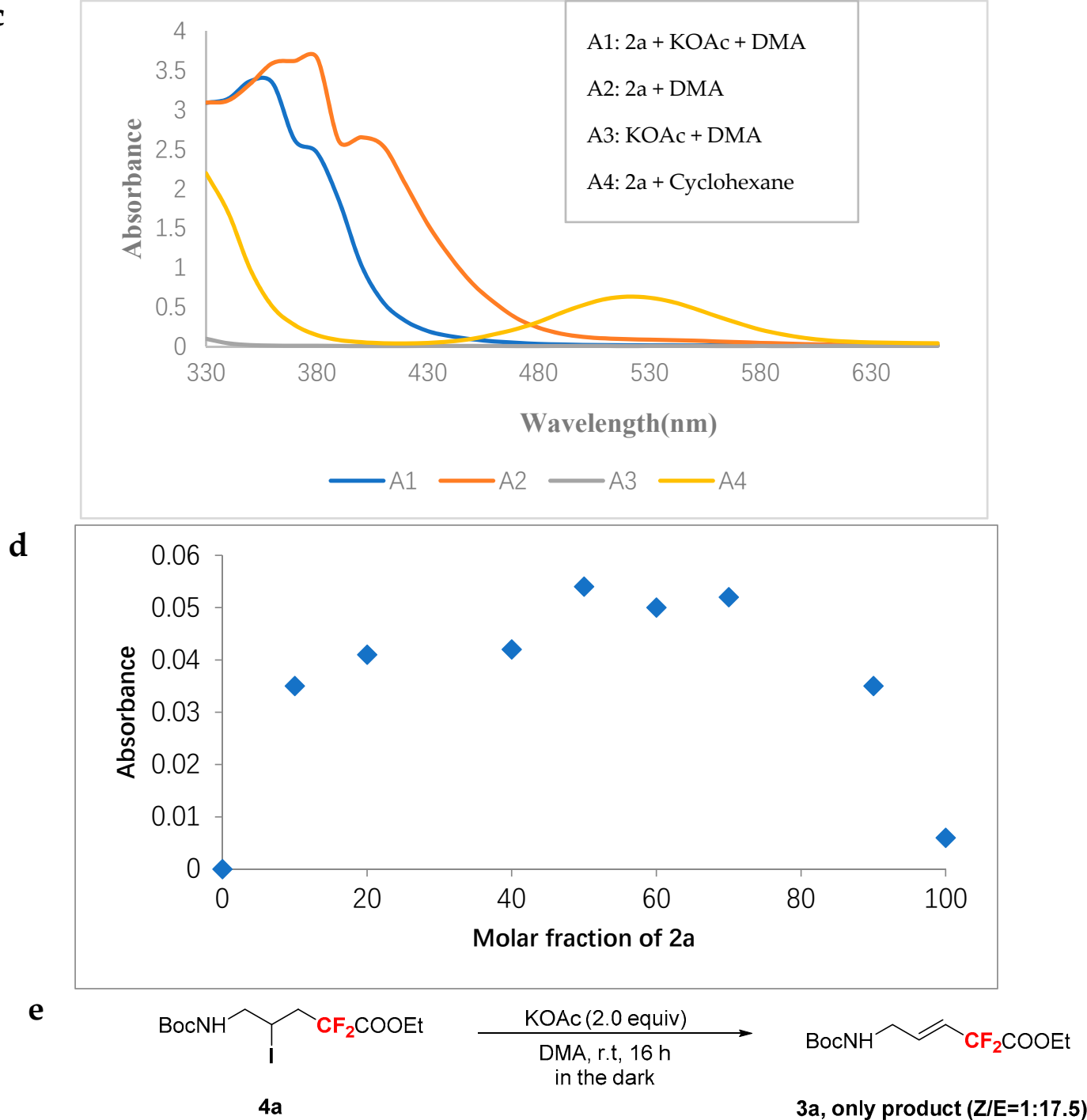

Scheme 2. Mechanistic investigation. (a) Addition of radical and SET inhibitors. (b) Trapping of intermediates. (c) Optical absorption spectra study. (d) Job's plot. (e) Control experiment.

Based on these preliminary results and previous reports [53,54], a plausible mechanism was depicted in Scheme 3. Initially, non-covalent interactions occurred between DMA and C-I bond. Then fluoroalkyl radical was generated under the irradition of purple LEDs. Subsequently, fluoroalkyl radical reacted with alkenes (1) and generated a carbon radical $\mathbf{A}$, which abstracted an iodine atom 
from $R_{F} I$ to afford ATRA product 4 along with $R_{F}$ radical that sustains the chain. Finally, elimination of 4 with base could afford the corresponding fluoroalkylated-ATRE products (3).

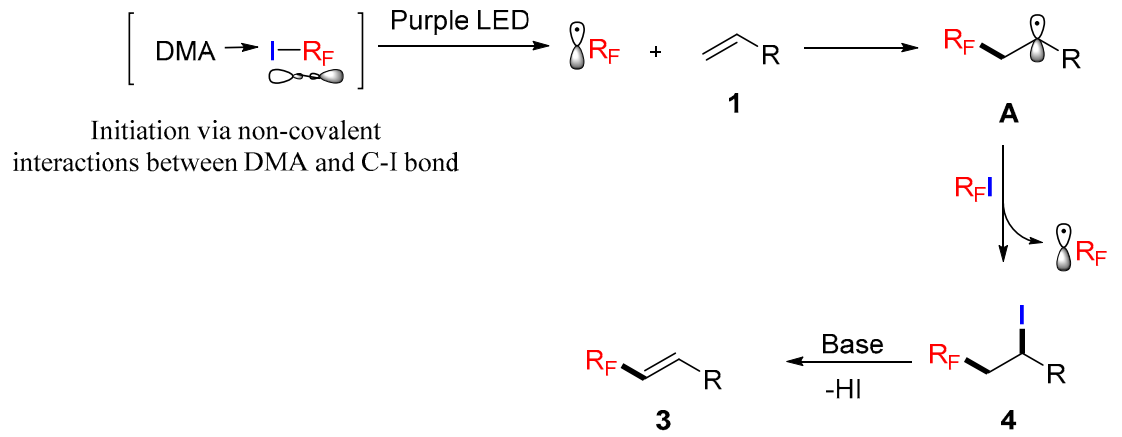

Scheme 3. Proposed Reaction Mechanism.

\section{Discussion}

In the past 10 years, fluoroalkylation involving visible light promoted reactions has emerged as an attractive and useful strategy to directly introduce fluorinated groups into organic molecules Among those methods, fluoroalkyl iodides were commonly used substrates. Based on the investigations in our group, we believe the noncovalent interaction between solvents (DMF, DMA, MeCN, acetone ect) and fluoroalkyl iodides might play a crucial role in this kind of transformation.

\section{Materials and Methods}

${ }^{1} \mathrm{H}$ NMR spectra and ${ }^{13} \mathrm{C}$ NMR spectra were recorded on an Agilent AM400 spectrometer. ${ }^{19} \mathrm{~F}$ NMR was recorded on an Agilent $400 \mathrm{MHz}$ NMR spectrometer $\left(\mathrm{CFCl}_{3}\right.$ as outside standard and low field is positive). Chemical shifts $(\delta)$ are reported in ppm, and coupling constants $(J)$ are in Hertz $(\mathrm{Hz})$. The following abbreviations were used to explain the multiplicities: $s=$ singlet, $d=$ doublet, $t=$ triplet, $\mathrm{q}=$ quartet, $\mathrm{m}=$ multiplet, $\mathrm{br}=$ broad. NMR yield was determined by ${ }^{19} \mathrm{~F}$ NMR using fluorobenzene as an internal standard before working up the reaction.

All reagents were used as received from commercial sources, unless specified otherwise, or prepared as described in the literature. All reagents were weighed and handled in air at room temperature. Blue LEDs (430-490 nm, peak wavelength: $455.0 \mathrm{~nm}$ ) and purple LEDs (380-425 nm, peak wavelength: $395.0 \mathrm{~nm}$ ) were bought online.

Supplementary Materials: The supplementary materials are available online.

Author Contributions: C.-Y.H. and X.-F.L. conceived and designed the experiments. W.-W.X., L.W. and T.M. performed the experiments and mechanism studies. C.-Y.H. and X.-F.L. co-wrote the manuscript. J.G. contributed for the edition of manuscript at revision stage. All authors discussed the results and commented on the manuscript. All authors have read and agreed to the published version of the manuscript.

Funding: We are grateful for the financial support from the National Natural Science Foundation of China (No. 21702241, 81760624, 21762053), Programs of Guizhou Province (No. 2017-1225, 2018-1427), Guizhou Provincial Science \& Technology “125-Plan” Major Project (No. 2015-039).

Conflicts of Interest: The authors declare no conflict of interest.

\section{References}

1. Purser, S.; Moore, P.R.; Swallow, S.; Gouverneur, V. Fluorine in medicinal chemistry. Chem. Soc. Rev. 2008, 37, 320-330. [CrossRef]

2. Müller, K.; Faeh, C.; Diederich, F. Fluorine in Pharmaceuticals: Looking Beyond Intuition. Science 2007, 317, 1881-1886. [CrossRef] [PubMed] 
3. Wang, J.; Sánchez-Roselló, M.; Aceña, J.L.; del Pozo, C.; Sorochinsky, A.E.; Fustero, S.; Soloshonok, V.A.; Liu, H. Fluorine in Pharmaceutical Industry: Fluorine-Containing Drugs Introduced to the Market in the Last Decade (2001-2011). Chem. Rev. 2014, 114, 2432-2506. [CrossRef] [PubMed]

4. Preshlock, S.; Tredwell, M.; Gouverneur, V. ${ }^{18}$ F-Labeling of Arenes and Heteroarenes for Applications in Positron Emission Tomography. Chem. Rev. 2016, 116, 719-766. [CrossRef] [PubMed]

5. O'Hagan, D. Understanding organofluorine chemistry. An Introduction to the C-F bond. Chem. Soc. Rev. 2008, 37, 308-319. [CrossRef] [PubMed]

6. Burgey, C.S.; Robinson, K.A.; Lyle, T.A.; Sanderson, P.E.J.; Dale Lewis, S.; Lucas, B.J.; Krueger, J.A.; Singh, R.; Miller-Stein, C.; White, R.B.; et al. Metabolism-Directed Optimization of 3-Aminopyrazinone Acetamide Thrombin Inhibitors. Development of an Orally Bioavailable Series Containing P1 and P3 Pyridines. J. Med. Chem. 2003, 46, 461-473. [CrossRef] [PubMed]

7. Grunewald, G.L.; Seim, M.R.; Lu, J.; Makboul, M.; Criscione, K.R. Application of the Goldilocks Effect to the Design of Potent and Selective Inhibitors of Phenylethanolamine $N$-Methyltransferase: Balancing $\mathrm{pKa}$ and Steric Effects in the Optimization of 3-Methyl-1,2,3,4-tetrahydroisoquinoline Inhibitors by $\beta$-Fluorination. J. Med. Chem. 2006, 49, 2939-2952. [CrossRef]

8. Meanwell, N.A. Synopsis of Some Recent Tactical Application of Bioisosteres in Drug Design. J. Med. Chem. 2011, 54, 2529-2591. [CrossRef]

9. Charpentier, J.; Früh, N.; Togni, A. Electrophilic Trifluoromethylation by Use of Hypervalent Iodine Reagents. Chem. Rev. 2015, 115, 650-682. [CrossRef]

10. Alonso, C.; Marigorta, E.M.; Rubiales, G.; Palacios, F. Carbon Trifluoromethylation Reactions of Hydrocarbon Derivatives and Heteroarenes. Chem. Rev. 2015, 115, 1847-1935. [CrossRef]

11. Tomashenko, O.A.; Grushin, V.V. Aromatic Trifluoromethylation with Metal Complexes. Chem. Rev. 2011, 111, 4475-4521. [CrossRef] [PubMed]

12. Chu, L.; Qing, F.-L. Oxidative Trifluoromethylation and Trifluoromethylthiolation Reactions Using (Trifluoromethyl)trimethylsilane as a Nucleophilic $\mathrm{CF}_{3}$ Source. Acc. Chem. Res. 2014, 47, 1513-1522. [CrossRef]

13. $\mathrm{Xu}, \mathrm{X} .-\mathrm{H}$.; Matsuzaki, K.; Shibata, N. Synthetic Methods for Compounds Having $\mathrm{CF}_{3}-\mathrm{S}$ Units on Carbon by Trifluoromethylation, Trifluoromethylthiolation, Triflylation, and Related Reactions. Chem. Rev. 2015, 115, 731-764. [CrossRef]

14. Feng, Z.; Xiao, Y.-L.; Zhang, X. Transition-Metal (Cu, Pd, Ni)-Catalyzed Difluoroalkylation via Cross-Coupling with Difluoroalkyl Halides. Acc. Chem. Res. 2018, 51, 2264-2278. [CrossRef] [PubMed]

15. Chatterjee, T.; Iqbal, N.; You, Y.; Cho, E.J. Controlled Fluoroalkylation Reactions by Visible-Light Photoredox Catalysis. Acc. Chem. Res. 2016, 49, 2284-2294. [CrossRef] [PubMed]

16. Yerien, D.E.; Barata-Vallejo, S.; Postigo, A. Difluoromethylation Reactions of Organic Compounds. Chem. Eur. J. 2017, 23, 14676-14701. [CrossRef] [PubMed]

17. Moschner, J.; Stulberg, V.; Fernandes, R.; Huhmann, S.; Leppkes, J.; Koksch, B. Approaches to Obtaining Fluorinated $\alpha$-Amino Acids. Chem. Rev. 2019, 119, 10718-10801. [CrossRef] [PubMed]

18. Shao, X.; Xu, C.; Lu, L.; Shen, Q. Shelf-Stable Electrophilic Reagents for Trifluoromethylthiolation. Acc. Chem. Res. 2015, 48, 1227-1236. [CrossRef]

19. Furuya, T.; Kamlet, A.S.; Ritter, T. Catalysis for Fluorination and Trifluoromethylation. Nature 2011, 473, 470-477. [CrossRef]

20. Yajima, T.; Ikegami, M. Metal-Free Visible-Light Radical Iodoperfluoroalkylation of Terminal Alkenes and Alkynes. Eur. J. Org. Chem. 2017, 2017, 2126-2129. [CrossRef]

21. Yu, C.; Iqbal, N.; Park, S.; Cho, E.J. Selective Difluoroalkylation of Alkenes by using Visible Light Photoredox Catalysis. Chem. Commun. 2014, 50, 12884-12887. [CrossRef]

22. Tang, X.-J.; Dolbier, W.R. Efficient Cu-catalyzed Atom Transfer Radical Addition Reactions of Fluoroalkylsulfonyl Chlorides with Electron-deficient Alkenes Induced by Visible Light. Angew. Chem. Int. Ed. 2015, 54, 4246-4249. [CrossRef] [PubMed]

23. Xu, T.; Cheung, C.W.; Hu, X. Iron-Catalyzed 1,2-Addition of Perfluoroalkyl Iodides to Alkynes and Alkene. Angew. Chem. Int. Ed. 2014, 53, 4910-4914. [CrossRef] [PubMed]

24. Behrends, I.; Baehr, S.; Czekelius, C. Perfluoroalkylation of Alkenes by Frustrated Lewis Pairs. Chem. Eur. J. 2016, 22, 17177-17181. [CrossRef] [PubMed] 
25. Nguyen, J.D.; Tucker, J.W.; Konieczynska, M.D.; Stephenson, C.R.J. Intermolecular Atom Transfer Radical Addition to Olefins Mediated by Oxidative Quenching of Photoredox Catalysts. J. Am. Chem. Soc. 2011, 133, 4160-4163. [CrossRef] [PubMed]

26. Wu, G.; von Wangelin, J.A. Stereoselective Cobalt-catalyzed Halofluoroalkylation of Alkynes. Chem. Sci. 2018, 9, 1795-1802. [CrossRef]

27. Beniazza, R.; Remisse, L.; Jardel, D.; Lastecoueres, D.; Vincent, J.-M. Light-mediated Iodoperfluoroalkylation of Alkenes/Alkynes Catalyzed by Chloride Ions: Role of Halogen Bonding. Chem. Commun. 2018, 54, 7451-7454. [CrossRef]

28. Rawner, T.; Lutsker, E.; Kaiser, C.A.; Reiser, O. The Different Faces of Photoredox Catalysts: Visible-Light-Mediated Atom Transfer Radical Addition (ATRA) Reactions of Perfluoroalkyl Iodides with Styrenes and Phenylacetylenes. ACS Catal. 2018, 8, 3950-3956. [CrossRef]

29. Magagnano, G.; Gualandi, A.; Marchini, M.; Mengozzi, L.; Ceroni, P.; Cozzi, P.G. Photocatalytic ATRA Reaction Promoted by Iodo-Bodipy and Sodium Ascorbate. Chem. Commun. 2017, 53, 1591-1594. [CrossRef]

30. Long, Z.-Y.; Chen, Q.-Y. The Activation of Carbon-Chlorine Bonds in Per- and Polyfluoroalkyl Chlorides: DMSO-Induced Hydroperfluoroalkylation of Alkenes and Alkynes with Sodium Dithionite. J. Org. Chem. 1999, 64, 4775-4782. [CrossRef]

31. Murakami, S.; Ishii, H.; Fuchigami, T. Electrosynthesis of Ethyl a,a-difluoro-a-(phenylseleno)acetate and its Photochemical Synthetic Application. J. Fluorine. Chem. 2004, 125, 609-614. [CrossRef]

32. Ghattas, W.; Hess, C.R.; Iacazio, G.; Hardre, R.; Klinman, J.P.; Reglier, M. Pathway for the Stereocontrolled $Z$ and $E$ Production of $\alpha, \alpha$-Difluorine-Substituted Phenyl Butenoates. J. Org. Chem. 2006, 71, 8618-8621. [CrossRef] [PubMed]

33. Tiwari, D.P.; Dabral, S.; Wen, J.; Wiesenthal, J.; Terhorst, S.; Bolm, C. Organic Dye-Catalyzed Atom Transfer Radical Addition-Elimination (ATRE) Reaction for the Synthesis of Perfluoroalkylated Alkenes. Org. Lett. 2017, 19, 4295-4298. [CrossRef] [PubMed]

34. Wang, X.; Zhao, S.; Liu, J.; Zhu, D.; Guo, M.; Tang, X.; Wang, G. Copper-Catalyzed C-H Difluoroalkylations and Perfluoroalkylations of Alkenes and (Hetero)arenes. Org. Lett. 2017, 19, 4187-4190. [CrossRef] [PubMed]

35. Feng, Z.; Min, Q.-Q.; Zhao, H.-Y.; Gu, J.-W.; Zhang, X. A General Synthesis of Fluoroalkylated Alkenes by Palladium-Catalyzed Heck-Type Reaction of Fluoroalkyl Bromides. Angew. Chem. Int. Ed. 2015, 54, 1270-1274. [CrossRef]

36. Xie, J.; Li, J.; Weingand, V.; Rudolph, M.; Hashmi, A.S.K. Intermolecular Photocatalyzed Heck-like Coupling of Unactivated Alkyl Bromides by a Dinuclear Gold Complex. Chem. Eur. J. 2016, 22, 12646-12650. [CrossRef]

37. Nappi, M.; Bergonzini, G.; Melchiorre, P. Metal-Free Photochemical Aromatic Perfluoroalkylation of $\alpha$-Cyano Arylacetates. Angew. Chem. Int. Ed. 2014, 53, 4921-4925. [CrossRef]

38. Fernández-Alvarez, V.M.; Nappi, M.; Melchiorre, P.; Maseras, F. Computational Study with DFT and Kinetic Models on the Mechanism of Photoinitiated Aromatic Perfluoroalkylations. Org. Lett. 2015, 17, 2676-2679. [CrossRef]

39. Kandukuri, S.R.; Bahamonde, A.; Chatterjee, I.; Jurberg, I.D.; Escudero-Adán, E.C.; Melchiorre, P. X-Ray Characterization of an Electron Donor-Acceptor Complex that Drives the Photochemical Alkylation of Indoles. Angew. Chem. Int. Ed. 2015, 54, 1485-1489. [CrossRef]

40. Guo, Q.; Wang, M.; Liu, H.; Wang, R.; Xu, Z. Visible-Light-Promoted Dearomative Fluoroalkylation of $\beta$-Naphthols through Intermolecular Charge Transfer. Angew. Chem. Int. Ed. 2018, 57, 4747-4751. [CrossRef]

41. Wang, Y.; Wang, J.; Li, G.-X.; He, G.; Chen, G. Halogen-Bond-Promoted Photoactivation of Perfluoroalkyl Iodides: A Photochemical Protocol for Perfluoroalkylation Reactions. Org. Lett. 2017, 19, 1442-1445. [CrossRef] [PubMed]

42. Helmecke, L.; Spittler, L.; Baumgarten, K.; Czekelius, C. Metal-Free Activation of C-I Bonds and Perfluoroalkylation of Alkenes with Visible Light Using Phosphine Catalysts. Org. Lett. 2019, 21, 7823-7827. [CrossRef] [PubMed]

43. Liu, Y.; Chen, X.-L.; Sun, K.; Li, X.-Y.; Zeng, F.-L.; Liu, X.-C.; Qu, L.-B.; Zhao, Y.-F.; Yu, B. Visible-Light Induced Radical Perfluoroalkylation/Cyclization Strategy To Access 2-Perfluoroalkylbenzothiazoles/Benzoselenazoles by EDA Complex. Org. Lett. 2019, 21, 4019-4024. [CrossRef] [PubMed]

44. Tu, H.-Y.; Zhu, S.; Qing, F.-L.; Chu, L. A Four-component Radical Cascade Trifluoromethylation Reaction of Alkenes Enabled by an Electron-donor-acceptor Complex. Chem. Commun. 2018, 54, 12710-12713. [CrossRef] [PubMed] 
45. Park, G.-R.; Choi, Y.; Choi, M.G.; Chang, S.-K.; Cho, E.J. Metal-Free Visible-Light-Induced Trifluoromethylation Reactions. Asian J. Org. Chem. 2017, 6, 436-440. [CrossRef]

46. Cheng, Y.; Yuan, X.; Ma, J.; Yu, S. Direct Aromatic C-H Trifluoromethylation via an Electron-Donor-Acceptor Complex. Chem. Eur. J. 2015, 21, 8355-8359. [CrossRef]

47. Postigo, A. Electron Donor-Acceptor Complexes in Perfluoroalkylation Reactions. Eur. J. Org. Chem. 2018, 46, 6391-6404. [CrossRef]

48. Zhao, L.; Huang, Y.; Wang, Z.; Zhu, E.; Mao, T.; Jia, J.; Gu, J.; Li, X.-F.; He, C.-Y. Organophosphine-Catalyzed Difluoroalkylation of Alkenes. Org. Lett. 2019, 21, 6705-6709. [CrossRef]

49. Zhu, E.; Liu, X.-X.; Wang, A.-J.; Mao, T.; Zhao, L.; Zhang, X.; He, C.-Y. Visible Light Promoted Fluoroalkylation of Alkenes and Alkynes using 2-Bromophenol as a Catalyst. Chem. Commun. 2019, 55, 12259-12262. [CrossRef]

50. Huang, Y.; Lei, Y.-Y.; Zhao, L.; Gu, J.; Yao, Q.; Wang, Z.; Li, X.-F.; Zhang, X.; He, C.-Y. Catalyst-free and Visible Light Promoted Trifluoromethylation and Perfluoroalkylation of Uracils and Cytosines. Chem. Commun. 2018, 54, 13662-13665. [CrossRef]

51. Mao, T.; Ma, M.-J.; Zhao, L.; Xue, D.-P.; Yu, Y.; Gu, J.; He, C.-Y. A General and Green Fluoroalkylation Reaction Promoted via Noncovalent Interactions between Acetone and Fluoroalkyl Iodides. Chem. Commun. 2020, 56. [CrossRef] [PubMed]

52. Li, K.; Zhang, X.; Chen, J.; Gao, Y.; Yang, C.; Zhang, K.; Zhou, Y.; Fan, B. Blue Light Induced Difluoroalkylation of Alkynes and Alkenes. Org. Lett. 2019, 21, 9914-9918. [CrossRef] [PubMed]

53. Cismesia, M.; Yoon, T. Characterizing Chain Processes in Visible Light Photoredox Catalysis. Chem. Sci. 2015, 6, 5426-5434. [CrossRef] [PubMed]

54. Buzzetti, L.; Crisenza, G.E.; Melchiorre, P. Mechanistic Studies in Photocatalysis. Angew. Chem. Int. Ed. 2019, 58, 3730-3747. [CrossRef]

Sample Availability: Not available.

(C) 2020 by the authors. Licensee MDPI, Basel, Switzerland. This article is an open access article distributed under the terms and conditions of the Creative Commons Attribution (CC BY) license (http://creativecommons.org/licenses/by/4.0/). 